\title{
Lung adenocarcinoma presenting as interstitial lung disease
}

\author{
Aditya Mehta (1) , Anandbir Bath (1) , Akshaya Gadre, Mark Schauer
}

Department of Internal Medicine, Western Michigan University Homer Stryker MD School of Medicine, Kalamazoo, Michigan, USA

\section{Correspondence to}

Dr Aditya Mehta; adimehta1009@gmail.com

Accepted 2 July 2020

\section{DESCRIPTION}

A 59-year-old Caucasian woman presented with a 3-month history of worsening dyspnoea and productive cough with clear mucoid sputum. She also had episodic chills, night sweats and an unintentional $11 \mathrm{~kg}$ weight loss. She denied any fever, haemoptysis, recent travel or sick contacts. Her history was significant for 40 pack-year tobacco abuse and multiple environmental exposures including sandblasting, insecticide and mould. The physical examination revealed a thin, cachectic woman in acute respiratory distress with tachycardia (124 beats/min) and tachypnea (30/min), saturating at $75 \%$ on ambient air. The pulmonary examination revealed diffuse bilateral inspiratory crackles, more noted on the right as compared with the left. The initial chest X-ray and CT scan (figure 1A,B) revealed extensive emphysema, the right-greaterthan-left consolidation and bilateral infiltrates with ground-glass attenuation. She was started on bi-level positive airway pressure and later switched to high-flow nasal cannula to maintain her saturation above $88 \%$. The patient's respiratory status worsened during the course of her hospitalisation. A repeat CT angiogram of the chest (figure 2A,B) which revealed worsening of the bilateral infiltrates with an increase in the size of right lower lobe consolidation. There was no evidence of pulmonary thromboembolism. Further workup including autoimmune panel, and a hypersensitivity pneumonitis panel, both were negative. Sputum and blood cultures for bacterial, fungal and acid-fast bacteria were also negative. She was treated with high dose steroids for presumed interstitial lung disease (ILD). Eventually, she underwent a transbronchial biopsy which was consistent with primary lung adenocarcinoma with lepidic and papillary growth patterns (figure 3).

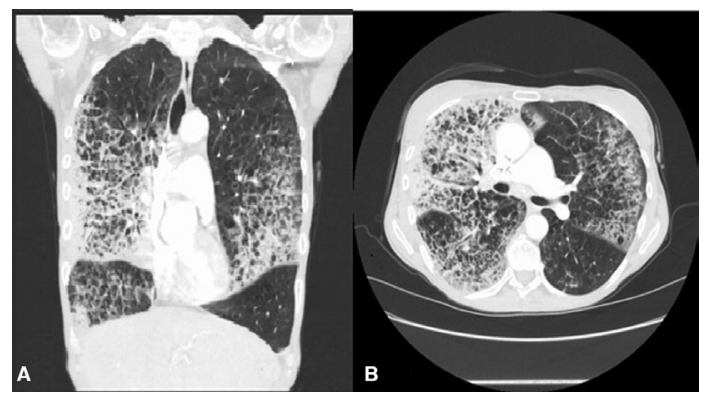

Figure 1 CT scan with contrast. Extensive bilateral emphysema with lung consolidation, the right greater than left. Diffuse interstitial reticular infiltrates. (A) Coronal section. (B) Axial section.

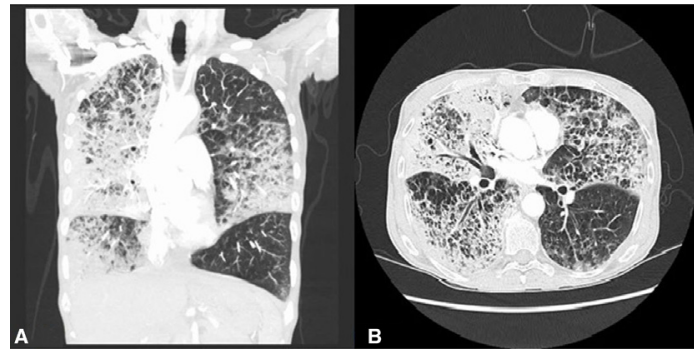

Figure $2 \mathrm{CT}$ angiogram. Worsening bilateral pulmonary infiltrates. Traction bronchiectasis and extensive emphysema can also be seen.

Lung adenocarcinoma represents about 50\% of all lung cancers and has a high prevalence in smokers. ${ }^{1}$ Other risk factors include family history, environmental exposures and toxic fumes. Our patient had a 40 pack-year history of tobacco smoking and environmental exposures which included sandblasting with carbide and silica, which put her at increased risk. The differential diagnosis of the findings seen on imaging includes cryptogenic organising pneumonia, chronic eosinophilic pneumonia, drug-induced pneumonitis and usual interstitial pneumonia which were ruled out early in the course. In our case, since the clinical presentation along with exposure history and imaging studies were suggestive of hypersensitivity pneumonitis, we started the patient on steroids which improved

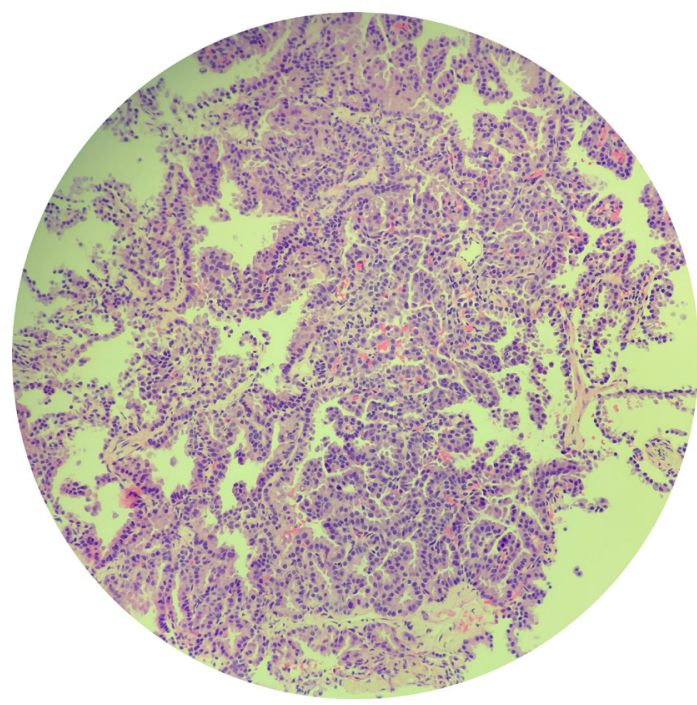

Figure 3 Transbronchial biopsy. The histopathological image from the right middle lobe showing bronchoalveolar carcinoma with lepidic pattern and cuboidal cells lining the alveoli. 


\section{Learning points}

- Lung adenocarcinoma has diverse clinical and radiological presentation and hence should always be on the differential when considering interstitial lung disease (ILD).

- Occupational exposures and smoking history are strong risk factors for ILD and lung cancer.

- Invasive diagnostic testing such as transbronchial and/or surgical biopsy should be sought early in the disease course to confirm the diagnosis.

her in the short term. Her worsening clinical status demanded further invasive workup, which revealed lung adenocarcinoma. This cancer usually presents as peripheral nodules. Rarely, it can present as an interstitial pattern, as seen in our case. Differential includes lymphangitic carcinomatosis; however, no neoplastic cells were found in perivascular, peribronchial and lymphatics. Adenocarcinoma masquerading as pneumonia, lung fibrosis with honeycombing and diffuse inflammatory ILD has been reported in the literature. ${ }^{2-5}$ The diffuse interstitial pneumonia-like pattern can be seen in metastatic tumours such as melanoma as well. ${ }^{6}$ Immunohistochemical studies following biopsy are usually warranted in such cases where the diagnosis is unclear despite optimum medical therapy for the presumed diagnosis.

Acknowledgements The completion of this undertaking could not have been possible without the participation and assistance of so many people whose names may not all be enumerated. Their contributions are sincerely appreciated and gratefully acknowledged. EF was involved in the acquisition of pathological images.

Contributors $A M, A B$ and $A G$ were involved in writing the manuscript. MS reviewed and proof-read the draft. The final manuscript was reviewed and approved by all the authors.

Funding The authors have not declared a specific grant for this research from any funding agency in the public, commercial or not-for-profit sectors.

Competing interests None declared.

Patient consent for publication Obtained.

Provenance and peer review Not commissioned; externally peer reviewed.

\section{ORCID iDs}

Aditya Mehta http://orcid.org/0000-0001-6932-2188

Anandbir Bath http://orcid.org/0000-0003-2341-6001

\section{REFERENCES}

1 Seer. SEEReer cancer statistics review 1975-2006 National cancer Institute SEER cancer statistics review 1975-2006 National cancer Institute. Cancer 2008:1975-2006.

2 Thompson WH. Bronchioloalveolar carcinoma masquerading as pneumonia. Respir Care 2004:49:1349-53.

3 Lantuejoul S, Colby TV, Ferretti GR, et al. Adenocarcinoma of the lung mimicking inflammatory lung disease with honeycombing. Eur Respir J 2004;24:502-5.

4 Pathak V, Hurtado Rendon IS. Pulmonary adenocarcinoma masquerading as diffuse inflammatory interstitial lung disease. Respir Med CME 2011;4:67-9.

5 Kunoor A, Balasuramoniam KR, Deepu M, et al. Pulmonary adenocarcinoma masquerading as ILD 2018;20:117-20.

6 Raparia K, Ketterer J, Dalurzo ML, et al. Lung tumors masquerading as desquamative interstitial pneumonia (DIP): report of 7 cases and review of the literature. Am J Surg Pathol 2014;38:921-4.

Copyright 2020 BMJ Publishing Group. All rights reserved. For permission to reuse any of this content visit

https://www.bmj.com/company/products-services/rights-and-licensing/permissions/

BMJ Case Report Fellows may re-use this article for personal use and teaching without any further permission.

Become a Fellow of BMJ Case Reports today and you can:

Submit as many cases as you like

- Enjoy fast sympathetic peer review and rapid publication of accepted articles

- Access all the published articles

- Re-use any of the published material for personal use and teaching without further permission

Customer Service

If you have any further queries about your subscription, please contact our customer services team on +44 (0) 2071111105 or via email at support@bmj.com.

Visit casereports.bmj.com for more articles like this and to become a Fellow 